\title{
SIGNIFICAC̣̃̃ES SOBRE DESENVOLVIMENTO HUMANO E ADOLESCÊNCIA EM UM PROJETO SOCIOEDUCATIVO
}

\author{
Cláudio Márcio de Araújo* \\ Maria Cláudia Santos Lopes de Oliveira**
}

RESUMO: Este artigo se baseia em uma pesquisa que teve por objetivo analisar concepções sobre adolescência e desenvolvimento humano que medeiam as intervenções socioeducativas no contexto de um circo social. Participantes: adolescentes, corpo técnico, estagiários e o próprio pesquisador. Os resultados foram gerados considerando os seguintes núcleos de significação: (a) a potencialidade da arte circense como instrumento na promoção de desenvolvimento humano; (b) a evolução no uso de instrumentos circenses como foco do processo de acompanhamento e avaliação do adolescente; (c) a adolescência como fase do ciclo de vida; (d) risco e vulnerabilidade social como características do sujeito ou do contexto. A necessidade de que os agentes institucionais busquem uma compreensão mais profunda do processo de transformação pessoal que tem lugar ao longo da adolescência é aspecto explorado na discussão.

Palavras-chave: Adolescência; Desenvolvimento Humano; Projeto Socioeducativo.

\section{MEANINGS AROUND HUMAN DEVELOPMENT AND ADOLESCENCE IN A SOCIAL EDUCATIVE PROJECT}

ABSTRACT: This article is based on a research aimed at analyzing conceptions around adolescence and human development mediating social educative interventions in the context of a social circus. Participants: adolescents; technical staff; trainees; and, the researcher himself. The results were generated considering the following meaning complexes: (a) the potential of circus techniques as mediation tools in promoting innovative trajectories of human development; (b) personal improvements in the domain of tools and techniques as the focus of the follow up and evaluation process of the adolescent; (c) adolescence as a stage of life cycle; (d) social risk and vulnerability alternating as characteristics of the subject or the context. The necessity that institutional agents search for a deeper comprehension of the process of personal transformation that takes place along adolescence is an important point of discussion.

Keywords: Adolescence; Human Development; Social-Educative Project.

\footnotetext{
* Mestre em Processos de Desenvolvimento Humano e Saúde do Instituto de Psicologia da Universidade de Brasília (UNB) e Professor substituto da Faculdade de Educação da Universidade Federal de Goiás (UFG).E-mail: claudioaraujo.filo@gmail.com ** Doutora em Educação pela Pontifícia Universidade Católica do Rio de Janeiro (PUC-RJ); Professora do Departamento de Psicologia Escolar e do Desenvolvimento e do Programa de Pós-graduação de Processos de Desenvolvimento Humano e Saúde da Universidade de Brasília (UNB). Pesquisadora do Laboratório de Microgênese das Interações Sociais (LABMIS) da Universidade de Brasília (UNB). E-mail: mcsloliveira@gmail.com
} 
O desenvolvimento humano caracteriza-se como fenômeno complexo, dinâmico e situado em marcos espaço-temporais concretos. Da mesma forma, ao integrar o processo de construção do ser humano, a adolescência deve ser compreendida à luz da dinâmica histórico-cultural das sociedades.

A complexidade das condições de desenvolvimento contemporâneas evoca a necessidade de pesquisas que abordem o conjunto sistêmico de transformações da pessoa no tempo, em referência às diferentes instituições que medeiam tal processo. Enquanto o contexto familiar e a escola são temas frequentes na investigação psicológica do desenvolvimento humano (MUNHOZ; MACIEL, 2008; RAPOSO; MACIEL, 2006; RAPOSO; MACIEL, 2007; TACCA; BRANCO, 2008; TACCA; GONZÁLEZ REY, 2008; SZELBRACIKOWSKI; DESSEN, 2007; DESSEN; POLONIA, 2007), as especificidades de outros contextos naturalísticos, tais como organizações sociais, instituições do sistema de assistência social e jurídico, são ainda pouco abordados. Baseando-se em dados de um estudo empírico realizado em 2007, o presente trabalho investiga como as noções de "desenvolvimento humano" e de "adolescência" são negociadas em diferentes dimensões de um projeto social educativo que visa à promoção social de adolescentes de camadas populares de uma região periférica de Goiânia (GO). Ademais, busca compreender como as significações sobre os temas ali negociadas afetam práticas institucionais que visam a promover mudança subjetiva entre os envolvidos. A discussão dos resultados do estudo é precedida de uma seção de fundamentação, na qual a perspectiva histórico-cultural serve de base para a compreensão das categorias adolescência e desenvolvimento humano.

\section{A psicologia sócio-histórica, o desenvolvimento humano e 0 fenômeno da adolescência}

A psicologia sócio-histórica, identificada por Vygotsky como teoria histórico-cultural, parte dos princípios filosóficos do materialismo histórico e dialético, e traz embutida uma teoria e um método científico que se contrapõem à leitura de ciência proposta pelo positivismo lógico (OZELLA, 2003). Vygotsky considerou a complexidade dos fenômenos 
psíquicos e encontrou sua gênese na cultura e na sociedade (VYGOTSKY, 1978; 1998; 2003), contextos esses que proporcionam a "transformação integrada e constante dos fenômenos mentais" (ORIONTE; SOUZA, 2007, p. 107). Suas reflexões e posicionamentos são marcados por uma insatisfação com a orientação idealista e materialista mecanicista que dominava a psicologia nos primeiros anos do século XX (MADUREIRA; BRANCO, 2005a).

De modo diverso, a psicologia histórico-cultural qualifica o desenvolvimento humano como

um processo dialético complexo, caracterizado pela periodicidade, desigualdade no desenvolvimento de diferentes funções, metamorfose ou transformação qualitativa de uma forma em outra, imbricamento de fatores internos e externos, e processos adaptativos que superam os impedimentos que a criança encontra (VYGOTSKY, 2003, p. 96).

O que se pode verificar é que, ainda que não abandone por completo a ideia de estágios ou ciclos de desenvolvimento humano, o teórico russo já apresentava, há cerca de um século, visão bastante inovadora do processo de desenvolvimento, ao contrariar a modelagem linear e objetivista predominante em Psicologia e postular que diferentes funções psicológicas emergem e se transformam em resposta a dificuldades e barreiras que o meio apresenta em cada circunstância particular. Da mesma forma, a psicologia sócio-histórica rejeita a ideia de uma natureza humana independente das formas culturais específicas, algo como uma essência universal do homem. Sua perspectiva é que, ao atuar em sistemas concretos de atividades, cada um constrói e reconstrói sua consciência, configurando o mundo externo historicamente constituído e compartilhado em realidade internalizada (ANDRIANI, 2003).

Desse modo, a atividade social mediada por instrumentos materiais e simbólicos é o contexto no qual o ser humano vivencia e se apropria da produção histórica da humanidade (ROSA, 2003), estabelece relações com a realidade cultural e com os outros homens, construindo a história e transformando a realidade (VYGOTSKY, 2003). Desse último argumento, inferimos que o outro social tem papel capital na mediação dos processos de desenvolvimento pessoal (OLIVEIRA, 1992) e que o desenvolvimento é parte de um processo de coconstrução, que se realiza em trocas do sujeito com o meio sociocultural, ao longo do tempo. Em 
virtude dessas características, a análise do desenvolvimento humano deve reportar-se aos processos, às cadeias de eventos históricos, que se configuram em intervalos temporais de maior ou menor porte, conforme o caso, processos que se tornam possíveis pela interação ativa entre sujeito e ambiente (VALSINER, 1989; VYGOTSKY, 2003).

Ao apontar para o caráter cultural da vida psíquica, a psicologia sócio-histórica busca compreender o homem como parte de sistemas de crenças e valores, que nele se refletem e orientam os desejos que ele experimenta e as motivações que o guiam (ARENDT, 2004; BRANCO; VALSINER, 1997). Traduzindo-se em sistemas de crenças, regras e normas sociais formais e informais, as quais são levadas a cabo em contextos institucionais concretos, a cultura ao mesmo tempo impõe limites e oferece possibilidades à conduta humana, guiando o desenvolvimento da pessoa em determinadas direções mais prováveis. Tais guias são apresentadas, via de regra, na forma de circunscritores sociais, que constituem o homem em interdependência com o contexto social e com as marcas de determinado corte histórico (AGUIAR; OZELLA, 2003).

Essas são ideias fundamentais para sustentar a compreensão que temos do fenômeno da adolescência, seu desenvolvimento e sua construção histórico-social.

Em torno do século XIX, a adolescência emergiu como um construto no discurso médico e pedagógico (GONDRA; GARCIA, 2004; LOPES DE OLIVEIRA, 2006), passando a ser definida tal como uma fase com características específicas, processos e comportamentos relativamente normativos e previsíveis (BOCK; LIEBESNY, 2003; BOCK, 2004), diferenciados da infância e da idade adulta (TEIXEIRA, 2003). É possível identificar, inclusive entre correntes da Psicologia, a adolescência retratada como fenômeno natural e universal, em abordagens que negligenciam sua inserção histórica e as condições concretas de vida em que se formam e transformam os sujeitos de dada geração (BOCK, 2007; OZELLA, 2003). As características que costumam ser atribuídas à adolescência, tal como turbulências emocionais e tendência à ação irrefletida, contribuem para sua desvalorização, especialmente quando comparada à vida adulta, fantasiosamente caracterizada como fase de conquista de estabilidade intelectual, equilíbrio emocional e produtividade econômica. Posicionamentos como esses revelam uma cultura adultocêntrica, em que é valorizado o modelo de adulto produtivo, adaptado e ordeiro, enquanto 
os não-adultos são marginalizados, objetos de menos-valia (BOCK, 2004).

Entretanto, enquanto sujeitos ativos, os adolescentes se mostram capazes de ultrapassar um modelo social que os exclui, idealiza e controla, e de se apresentarem como autores de si próprios, construindo novas formas de ser, ao criar possibilidades existenciais, sociais e políticas inovadoras (MAGRO, 2002; OZELLA, 2003; LOPES DE OLIVEIRA, 2006).

Sendo assim, o desinteresse no aprofundamento do estudo da adolescência contribui para a fomentação de visões estereotipadas, distorcidas e fragmentadas do adolescer (LOPES DE OLIVEIRA, 2006), o que torna relevante e necessária a realização de investigações críticas sobre o desenvolvimento adolescente, especialmente estudos que tomem por base contextos socioinstitucionais que contradizem as construções históricosociais dominantes em torno da adolescência. Portanto, a reflexão sobre o papel de instituições de atendimento, como contextos de educação e desenvolvimento de crianças e adolescentes, mostra-se relevante e necessária, como contribuição para a efetiva defesa de seus direitos sociais, políticos e pessoais, assim como proposto pelo Estatuto da Criança e do Adolescente (ECA). O presente estudo interessa-se pela compreensão do desenvolvimento de adolescentes que vivem em situação de pobreza e são a clientela de um projeto social de promoção da cidadania, por meio de técnicas circenses. As especificidades do adolescer em tais condições são tratadas na seção que se segue.

\section{Adolescência, pobreza e intervenções sociais}

O Estatuto da Criança e do Adolescente (ECA), lei n. 8.069, de 13 de julho de 1990, nasceu com a vocação de regulamentar os direitos sociais de crianças e adolescentes. No que se refere a esses últimos, o ECA propõe a co-responsabilidade do Estado e da sociedade civil na promoção de condições adequadas para o seu desenvolvimento. Diferentemente de dispositivos legais anteriores, o ECA orienta-se pelo paradigma da proteção, preocupando-se com o desenvolvimento global de todos, mas especialmente daqueles que se encontram em situação de risco social ou pessoal. 
Conforme Santos (2004, p. 229), “[a]pesar do ineditismo e dos avanços teóricos e sociais propostos pela nova lei - ECA -, assistimos atualmente a um quadro em que a utopia preconizada ainda está muito longe de seu projeto original". O autor ressalta que, especialmente, crianças e adolescentes que vivem em condições socioeconômicas precárias ainda são, muitas vezes, criminalizadas, vistas pela sociedade, em geral, como marginais em potencial, fontes de perigo. Por implausível que pareça, semelhante visão é encontrada também em algumas instituições do sistema público de atendimento a adolescentes em risco social (a exemplo dos autores de infração, vivendo fora da família e da escola, nas ruas). Espíndula e Santos (2004) identificam, nos documentos e discursos que circulam em instituições por eles investigadas, que os adolescentes são categorizados como coitados, vítimas de uma infância e de uma adolescência "diferentes", estigmatizados e sem muitas perspectivas de futuro. Em outras palavras, essas instituições conservam valores e crenças presentes no Código do Menor, de 1929, e demais legislações anteriores ao ECA.

Vemos aí uma situação contraditória: como parte do Estado, tais instituições deveriam ser cúmplices do papel de proteger e promover o desenvolvimento de adolescentes e jovens, entretanto contribuem para reproduzir formas várias de preconceito e exclusão. $O$ trabalho de Teixeira (2003) interessa-se pelas intervenções realizadas por um tipo novo de organização da sociedade civil, que passou a se proliferar no âmbito da assistência social e ações socioeducativas com adolescentes e jovens a partir da promulgação do ECA, as chamadas ONGs (organizações não-governamentais) e OSCIPs (organizações da sociedade civil de interesse público). As ações desses grupos, como sabemos, não são livres de contradições e podem também contribuir para a reprodução de condições de exclusão social do adolescente, como notou o estudo de Espíndula e Santos (2004). No entanto, há também uma realidade ainda pouco documentada, de organizações civis que buscam ativamente realizar intervenções de qualidade, ajustando-se a uma realidade social complexa, que requer delas grande habilidade de adaptação a novas funções e papéis (VECTORE, 2005). Esses novos contextos institucionais e seus programas de atendimento passaram a configurar ambientes importantes na promoção de desenvolvimento de um número crescente de crianças e adolescentes oriundos de camadas populares (SANTANA; DANINELLI; 
FROSI; KOLLER, 2005). Em muitos casos, as crianças e os adolescentes encontram ali a principal forma de acesso a meios simbólicos capazes de fazê-los ultrapassar a condição desfavorável em que se vivem, desenvolvendo sua autoestima e chegando a angariar reconhecimento comunitário.

Desse modo, e coerente com a perspectiva sócio-histórica, desenvolvemos o presente estudo, com o objetivo de analisar a relação entre as concepções sobre adolescência e desenvolvimento presentes em um projeto social educativo e as práticas de promoção de desenvolvimento social ali implementadas. O projeto estudado utiliza técnicas circenses como meio de promoção de desenvolvimento e inserção social de adolescentes, doravante denominado EMSC (ou "Escola Minha Segunda Casa", codinome atribuído ao projeto pelos pesquisadores em referência à caracterização dada a ele por vários dos adolescentes participantes do estudo).

A investigação, de caráter qualitativo, caracteriza-se pela interpretação, o que exige a imersão intensiva do pesquisador no contexto da pesquisa (KAPLAN; DUCHON, 1988). Desse modo, não existe conhecimento a priori. Ele é construído dentro de uma temporalidade, sendo "infectado" pelo contexto sociocultural, no qual se insere o próprio pesquisador, o qual constrói conhecimentos dentro dos limites e possibilidades interpretativas socialmente constituídas (MADUREIRA; BRANCO, 2005b).

$\mathrm{Na}$ pesquisa qualitativa, a metodologia não é somente um caminho na busca do conhecimento, mas parte de um processo cíclico e dinâmico (BRANCO; ROCHA, 1998), que tem por mediadores os instrumentos e procedimentos utilizados na construção de informações. Desse modo, resultados não podem ser encarados como representando diretamente o objeto estudado, mas dispositivos com os quais o pesquisador trabalha para a construção de conhecimentos socialmente relevante (GONZÁLEZ REY, 2005). Por tudo isso o pesquisador se torna um participante da pesquisa, visto que suas hipóteses estão pautadas em um modelo teórico que, no encontro com a realidade investigada, busca construir conhecimento, e não coletá-los. Segundo a Epistemologia qualitativa, a participação do pesquisador na construção do conhecimento é marcada por sua história de vida, por suas crenças, seus valores e perspectivas pessoais, sendo assim um processo de construção interpretativa do conhecimento (GONZÁLEZ REY, 2005).

No presente estudo, os mediadores metodológicos foram a leitura de documentos institucionais, as observações etnográficas e entrevis- 
tas semiestruturadas, que levaram às significações sobre o desenvolvimento humano e de adolescência que orientam as práticas e intervenções no contexto institucional investigado. A interpretação das informações obtidas envolveu os três momentos de modo integrado, atendendo a uma triangulação metodológica.

Para Bauer e Aarts (2002), documentos retratam a intencionalidade de seus construtores. Portanto, devem ser analisados como eventos inseridos em um contexto sócio-histórico particular e que fornecem pistas sobre as significações que, na linha do tempo, medeiam as práticas realizadas naquele contexto. Já a observação participante (ou etnográfica) tem como um de seus pressupostos básicos a imersão do pesquisador no campo a ser estudado, o que possibilita o estabelecimento de relações pessoais e sociais qualitativamente significativas. Por sua vez, a entrevista semiestruturada contribui com o "desenvolvimento e a compreensão das relações entre os atores sociais e sua situação" investigada (GASKELL, 2002 , p. 65). Ela permite construir conhecimento sobre as significações dos atores institucionais, considerando suas crenças, atitudes, motivações e seus valores construídos em interdependência com o contexto, assim como as canalizações socioinstitucionais específicas que os condicionam.

Participaram da pesquisa: (a) 36 adolescentes, integrantes e exintegrantes de um projeto social educativo da cidade de Goiânia (GO), com idade entre 12 e 21 anos; (b) profissionais e estagiários que trabalhavam na instituição no período da pesquisa, bem como (c) o próprio pesquisador.

A seleção da instituição seguiu-se a um levantamento das instituições da sociedade civil atuando em ações socioeducativas com adolescentes na cidade de Goiânia. Caracteriza-se como campo de extensão, estágio e pesquisa, mantido por uma universidade do sistema privado de ensino da cidade, o que favorece inserção de pesquisadores de diferentes áreas em seu contexto

Foram incluídos como participantes deste estudo todos os sujeitos que se fizeram presentes na instituição investigada no período da realização das observações etnográficas (incluindo adolescentes, educadores e colaboradores) e mais dois jovens, ex-participantes da EMSC. Estes últimos foram selecionados entre as fichas de cadastro, arquivadas na instituição. As entrevistas foram realizadas com os atuais e ex-participantes do projeto que acataram o convite do pesquisador. 
(Re)construindo as significações institucionais

e de seus atores sobre desenvolvimento humano e adolescência

O fenômeno da significação diz respeito à convencionalização de formas de interpretar a realidade pelos sujeitos, considerando o imbricamento de aspectos pessoais, sociais, políticos e culturais (SILVA; ROSSETTI-FERREIRA; CARVALHO, 2004). Significações "são marcas ou efeitos que se produzem e impactam os sujeitos na relação" (SILVA; ROSSETTI-FERREIRA; CARVALHO, 2004, p. 43). Compreendemos as práticas sociais e a experiência partilhada como lugares em que relações interpessoais se desenvolvem, nos quais as possibilidades de significação estão ancoradas e onde acabam por se legitimar e consolidar (SMOLKA, 2004). Nesse sentido, significações são o resultado de uma construção coletiva que se dá a partir de interações entre os sujeitos em contextos situados. Para efeito de orientar as análises, separamos as significações sobre "desenvolvimento humano" e "adolescência" originárias de observação direta de atividades, textos normativos, projetos institucionais, entrevistas e interações informais estabelecidas em situação de pesquisa com coordenação e educadores sociais, que servem de conteúdo ao eixo "significações institucionais", e aquelas extraídas de enunciados ocorridos em interações informais e em situação de entrevista semiestruturada com adolescentes, cujo eixo de análise denominamos "significações elaboradas pelos adolescentes". No presente trabalho, focamo-nos no eixo das significações institucionais, por compreender que elas têm importante papel na organização da ação institucional, bem como em seus resultados, devendo ser bem-compreendidas a fim de balizar e avaliar os efeitos das intervenções institucionais, na linha do tempo. $\mathrm{Na}$ análise das informações oriundas desse eixo foram identificados os seguintes núcleos de significação sobre desenvolvimento humano e adolescência: (a) a potencialidade da arte circense como instrumento na promoção de desenvolvimento humano; (b) a evolução no uso de instrumentos circenses como foco do processo de acompanhamento e avaliação do adolescente; (c) a adolescência como fase do ciclo de vida; (d) risco e vulnerabilidade social como características do sujeito ou do contexto. 


\section{A potencialidade da arte circense como instrumento na promoção de desenvolvimento humano}

O projeto social educativo pesquisado envolve atividades educacionais com diferentes objetivos. São realizadas oficinas de arte circense, atividades esportivas, grupos de apoio psicopedagógico para a abordagem de dificuldades escolares, assim como atendimento psicológico e fisioterápico, nos casos indicados. A mais valorizada delas é a oficina de arte circense, que também constitui o recurso metodológico preferido pelos adolescentes atendidos na EMSC ( $\left.\mathrm{PP}^{1}\right)$. O uso das técnicas circenses como mediador do desenvolvimento de adolescentes e jovens não é exclusivo do projeto investigado. Lobo e Cassoli (2006) identificaram no Brasil um número considerável de trabalhos desenvolvidos sob o enfoque do circo social, o mais conhecido deles, a Escola Nacional de Circo, criada em 1982 pelo circense Luís Olimecha, no Rio de Janeiro. Segundo o texto de seu projeto pedagógico, na EMSC, as atividades circenses têm como objetivo principal despertar a sensibilidade do adolescente, propondo-lhe constantes desafios ao trabalhar "o domínio do corpo, a psicomotricidade, expressão corporal e facial, o equilíbrio, o improviso, a autodisciplina e também suas limitações" (PP, p. 7). A crença na eficácia da metodologia do circo social para alterar o curso de desenvolvimento dos adolescentes permeia os documentos norteadores do trabalho na EMSC. Tal crença canaliza comportamentos e atitudes, bem como concepções sobre desenvolvimento humano, naquele espaço: “(...) a arte circense tem permitido, no cotidiano das crianças e adolescentes, construir situações mediadoras que no dia-a-dia da escola tornam-se perspectiva para transformação na vida das crianças e adolescentes (PCR 2 , p. 68).

Embora a formação do artista circense não seja definida como o principal objetivo da EMSC (PRC, PP), grande parte de sua dinâmica cotidiana gira em torno dessa metodologia, o que subsidia a criação de inúmeras situações mediadoras (treinos, apresentações públicas internas e externas, entre outras) e fomenta a crença no papel redentor do circo para a transformação de vidas, uma visão que Lobo e Cassoli (2006) identificam entre muitos profissionais que trabalham na perspectiva do circo social. Por meio dele, a EMSC espera que os sujeitos sejam capazes de se descobrirem cidadãos, indo além dos desafios físicos, próprios ao aperfeiçoamento dessa arte, e chegando a posicionamentos em que se reconhe- 
çam e sejam reconhecidos como protagonistas da própria história, e não meros figurantes. Segundo um dos profissionais do projeto: "Espera-se que a criança e o adolescente não desafiem apenas a gravidade, mas também os problemas e obstáculos da vida, potencializando cada vez mais a compreensão do seu estar no mundo" (Cagaita³, observação).

Subjaz aí a significação da arte circense como metáfora do equilíbrio psíquico, instrumento eficaz na formação de cidadãos conscientes, capazes de se transformar e serem transformados. Outros enunciados colhidos vão nessa mesma direção:

Dentro dessa arte circense a gente ensina o equilíbrio da vida (Gabiroba, entrevista);

A arte circense nos ensina a enfrentar desafios brincando, aqui e lá na sala de aula. Nos ajuda a sermos persistentes com nossos sonhos (Cagaita, observação).

Entende a EMSC que o aperfeiçoamento na utilização dos instrumentos (físicos e simbólicos) relacionados às artes circenses contribui para desenvolver integralmente o sujeito e para a construção de sua cidadania, a obtenção de reconhecimento social e pessoal e o protagonismo infanto-juvenil, ao potencializar comportamentos mais proativos dos adolescentes frente ao contexto sociocultural em que vivem: "E essa questão dos equipamentos e o comportamento, isso influencia. A questão do trabalhar com os equipamentos da arte circense influencia no comportamento" (Mangaba, entrevista).

Desse modo, pretende-se que as técnicas circenses não apenas levem os adolescentes a criar possibilidades inovadoras de ação, mas reflitam sobre seus limites e busquem ultrapassar sempre mais as possibilidades experimentadas no uso de instrumentos circenses. Ademais, espera-se que levem tal reflexão a outros contextos, como a escola e a família, contribuindo para transformar seus contextos de origem. Como toda atividade humana, a arte circense aglutina significados culturais, sociais e pessoais. A expectativa é que o sujeito encontre nela meios para configurar ativamente o mundo externo em interno, ressignificando a si mesmo, e reconstruindo sua consciência (ANDRIANI, 2003):

...trabalhar com a arte circense, que exige muito equilíbrio, concentração, organização, né? ...Então a gente relaciona isso muito com a vida. (Gabiroba, interação informal) 
...os equipamentos circenses, a gente utiliza como ferramenta mediadora mesmo. Para o resgate da cidadania, assim, de tentar trabalhar com eles a questão da formação para a vida mesmo. (Mangaba, entrevista)

A concepção de socialização e educação adotada no trabalho desenvolvido pela [EMSC] fundamenta-se na perspectiva histórico cultural de Vygotsky, cuja teoria pauta-se na compreensão de um homem como ser histórico, que se constitui por meio de suas relações com o mundo natural e social (PCR, p. 46).

Tanto os profissionais da EMSC quanto os documentos orientadores de seu trabalho correlacionam a arte circense no trabalho social educativo com concepções de desenvolvimento humano.

Observa-se que a noção de desenvolvimento humano veiculada na instituição remete a um processo integrado, visto de forma dinâmica e complexa, o que é coerente com perspectivas contemporâneas no enfoque do tema (VALSINER 1987; 1989). Desenvolvimento é considerado o efeito de influências bidirecionais e que, no processo de socialização, o sujeito é ativo intérprete de informações (VALSINER, 1989; VALSINER, 1994a; VASCONCELLOS; VALSINER, 1995). Prevalecem posicionamentos nos quais os processos de desenvolvimento são interdependentes da cultura. Dessa forma, o discurso institucional da EMSC parece desvelar uma ideia de desenvolvimento que resulta da interdependência sujeitocontexto, na qual ambos "constituem-se como participantes ativos na configuração da subjetividade do ser em desenvolvimento" (PALMIERI; BRANCO, 2004, p. 193), trazendo reflexos em ambientes outros, tal como expressa Mangaba, em situação de entrevista: "isso traz reflexo na família, na escola, na sua vida pessoal".

\section{A evolução no uso de instrumentos circenses como foco do processo de acompanhamento e avaliação do adolescente}

A forma como concebemos o processo de avaliar reflete tanto nossas concepções pessoais quanto significações construídas no contexto educativo. Aquilo que escolhemos para avaliar e o que deixamos fora de nosso campo avaliativo dizem muito das significações que orientam nossas ações e atitudes em intervenções educacionais. Ao mesmo tempo, a forma como pensamos e agimos em contexto é, frequentemente, deter- 
minada pela linguagem que utilizamos para ler o mundo (MACLAREN, 2000).

Os documentos direcionadores do projeto estudado prezam uma concepção de avaliação abrangente, traduzida em três níveis a que denominam "avaliação de impacto", "avaliação de processo" e "avaliação de resultado". A avaliação de impacto constitui um balanço geral "para verificar se o projeto atingiu suas finalidades gerais" (PCR, p. 74) e dimensionar seus vários níveis de efeito nas áreas em que se propõe incidir, particularmente, no que concerne a seus principais beneficiários. A avaliação de processo mede a eficiência das operações do projeto, analisando o acerto da ação planejada, verificando a possibilidade da continuação da ação, bem como subsidiando o planejamento de novas ações. Por sua vez, a avaliação de resultados está orientada para os objetivos específicos do projeto, buscando verificar o alcance dos resultados desejados, por meio de um balanço entre as realizações buscadas em dado intervalo de tempo e o que foi alcançado (PCR).

Dessas três modalidades de avaliação, interessa-nos particularmente a primeira, que expressa o cuidado com os beneficiários do projeto. Contudo, o que se constatou no processo de imersão etnográfica foi a carência de um sistema avaliativo que consiga apreender, de forma qualitativa e intencional, o impacto das atividades que agregam a metodologia no desenvolvimento integral do adolescente. Não se observa ali uma sistemática de avaliação que capte as constantes organizações e reorganizações do sujeito, na linha do tempo, e que tendem a ocorrer como efeito das novas interações sociais e experiências que vivenciam no contexto do projeto (BRANCO; VALSINER, 1997; BRUNER, 2002). A avaliação, tal como configurada nos documentos analisados, enfatiza a preocupação com a organização interna da instituição: as operações do projeto, os resultados globais. A contribuição do adolescente no melhoramento do grupo (PCR, PP) é também monitorada, mas não se identificam procedimentos avaliativos focados na pessoa do adolescente, deixando-se de atentar para os processos de mudança pessoal em andamento.

A ausência de uma sistemática de avaliação formal e intencional, entretanto, não parece impedir que, de modo informal, procedimentos avaliativos orientados para o desenvolvimento ocorram no cotidiano da EMSC. Estes, porém, focam-se na evolução técnica do aluno, em suas conquistas em termos das habilidades no uso dos instrumentos circenses. 
É o caso do enunciado a seguir, que versa sobre o espetáculo de final de ano:

O espetáculo, um momento de avaliação também, serve também como momento de avaliação, para saber como está a criança, o desenvolvimento da criança, mas... em relação ao equipamento mesmo: como que ele evoluiu, ele começou no rola-rola, só com um no início, ele está subindo no rola-rola; já está fazendo evolução no rola-rola, então isso foi feito com os equipamentos. Agora esse da avaliação das crianças não é feito tão sistemático como deveria ser feito... (Mangaba, entrevista)

A mesma significação identifica-se em outros enunciados:

Tem menino que quando chega aqui não consegue nem subir em um rolarola... com o tempo ele se desenvolve e já faz vários instrumentos circenses. (Gabiroba, interação informal)

$\mathrm{O}$ adolescente nos indica como ele está por meio dos instrumentos que ele vai conseguindo trabalhar, aprender. Assim, sabemos se está adiantando ele vir para o projeto, ou não. (Cagaita, interação informal)

Em síntese, tanto as falas dos profissionais quanto as práticas institucionais cotidianas priorizam a avaliação do desenvolvimento do artista circense, no que se refere ao controle do corpo e ao manejo de técnicas, em detrimento de uma avaliação que enfoque o desenvolvimento integral do sujeito, analisando sua desenvoltura social e sua capacidade no protagonizar o próprio desenvolvimento, aspectos dados como a finalidade do projeto (PCR, PP).

A contradição desvelada no fato de o foco avaliativo não estar centrado nos fins do projeto, ou seja, no desenvolvimento integral dos sujeitos que dele participam, mas nos meios, no caso, as técnicas circenses, pode levar a posicionamentos descomprometidos com resultados realmente significativos no que diz respeito ao impacto do projeto na trajetória de vida do sujeito.

Essa reflexão é importante não só no contexto da EMSC, mas em outros que trabalham com a promoção intencional de desenvolvimento humano. O desenvolvimento não é previsível nem unilinear. É processo multifacetado que, no caso da instituição estudada, não depende apenas do querer dos educadores e do contexto institucional. Depende de um imbricado de processos detonados ao longo da história de vida daquele sujeito, bem como de outros contextos que vivencia, como escola, família, grupos e sociedade em geral. 


\section{A adolescência como fase do ciclo de vida}

No discurso institucional da EMSC, a noção de adolescência emerge em meio a um núcleo de concepções e práticas contraditórias, ora sendo vista como processo configurado sob condições sócio-históricas específicas, ora segundo o modelo naturalista e universalista hegemônico, portanto, desvinculada dos contextos culturais concretos nos quais e pelos quais a adolescência se constitui.

Os documentos institucionais revelam pouco sobre as concepções de adolescência que orientam o trabalho, e o que é apresentado denota desconhecimento de teorias contemporâneas sobre o assunto. Nota-se, muitas vezes, uma redução dos processos de desenvolvimento ao que é sugerido pelo Estatuto da Criança e do Adolescente (lei n. 8.069, de 13 de julho de 1990): “o Estatuto representa um dos instrumentos que apontam transformações em curso sobre a forma de se perceber a criança no mundo de hoje" (PCR, p. 24).

A ausência de uma discussão crítica do fenômeno da adolescência no contexto institucional estudado corresponde ao lugar secundário que lhe é reservado também por estudiosos do desenvolvimento humano, aspecto ressaltado por distintos pesquisadores (LOPES DE OLIVEIRA, 2003; 2006; OZELLA, 2003; SANTANA; DONINELLI; FROSI; KOLLER, 2004). A proliferação de visões normativas e moralizantes dos processos adolescentes perpetua-se no discurso dos profissionais, conforme os enunciados a seguir, obtidos em situação de entrevista:

\footnotetext{
Nossa, ser adolescente? Acho que ser adolescente é se descobrir, né? Assim, vou tirar por mim. A minha adolescência, eu me descobri. Apesar de eu ser muito agitada... eu fazia muita coisa assim, mas eu parava muito para pensar também. (Gabiroba, entrevista)

Tem aqueles que passam pela adolescência e parece que pra eles é tão normal, tão tranquilo que acho que eles nem sabem que estão nessa fase da adolescência. Acho que alguns acontecem como aconteceu comigo, eu passei e não sabia que estava na fase. (Mangaba, entrevista)
}

Um aspecto que se destaca entre os profissionais, tanto do que emergiu nas sessões de observação etnográfica quanto nas entrevistas realizadas, é que sua concepção de adolescência é constituída, quase exclusivamente, com base nas experiências particulares, saberes do senso comum 
e conhecimentos práticos, sem a mediação de reflexões teóricas mais aprofundadas. O efeito é uma adolescência concebida como processo natural, na qual o desenvolvimento aparece divorciado da realidade material e das práticas sociais concretas (BOCK, 2007; LOPES DE OLIVEIRA, 2006). Desequilíbrio, instabilidade e conflitos intra e interpessoais são os indicadores apontados para caracterizar a fase da adolescência, sem os quais muitos "nem sabem que estão nessa fase da adolescência” (Mangaba, entrevista). Portanto, a vivência da adolescência é reduzida a um fenômeno natural, definida em torno de comportamentos, sentimentos e atitudes comuns (BOCK, 2004; OZELLA, 2003). Conforme Ozella e Aguiar (2008, p. 100), concepções que naturalizam a presença de crise na adolescência acabam por "camuflar a realidade, as contradições sociais, as verdadeiras mediações que constituem tal fenômeno".

No caso da EMSC, a visão de adolescência simplista e reducionista que prevalece entre os profissionais desencoraja reflexões mais críticas sobre os processos em que atuam. Importantes para a compreensão da clientela e para a própria promoção do desenvolvimento dos adolescentes atendidos, este deveria constituir o objetivo último do projeto social (OZELLA; AGUIAR, 2008; OZELLA, 2003).

É importante salientar que, juntamente com as visões citadas, também se pode encontrar no discurso institucional a preocupação de prover aos adolescentes um lugar aberto à expressão, à participação e à construção de conhecimentos. Por exemplo, diz o projeto pedagógico que ali "é um local onde há espaço aberto ao diálogo, tanto com os colegas quanto com a equipe" (PP, p. 2). Em outro trecho, encontramos:

Trabalha-se, portanto, na perspectiva de contribuir com a formação do cidadão crítico, capaz de questionar a realidade. Neste sentido a criança e o adolescente, são vistos como sujeitos de direitos, capazes de transformar sua própria realidade (PCR, p. 47).

Talvez pelas brechas engendradas por essas exceções, é coerente afirmar que o contexto da EMSC, potencialmente, proporciona ao adolescente oportunidade de se constituir como pessoa na e pela atividade, a qual reflete a relação dialética entre sociedade e história, e na qual o sujeito se revela, ao mesmo tempo, único, singular e histórico (OZELLA; AGUIAR, 2008). Por essa razão, o discurso institucional valoriza a voz do 
adolescente e sua participação na coconstrução da própria cidadania, em que ele se mostra capaz de transformar os contextos e a realidade que vivencia. A evidência de que tal produz efeito é a alta motivação dos adolescentes para a participação no projeto, o elevado tempo de permanência vinculado a ele (média de 4 anos) e a avaliação positiva que fazem da experiência de participação, aspectos esses que são objeto de outro trabalho dos autores, em elaboração.

Esses parecem-nos indicadores relevantes da eficácia de uma mediação institucional que se mostra adequada à promoção do desenvolvimento da autonomia, do trabalho em grupo e da responsabilidade compartilhada entre os participantes do projeto.

\section{Risco e vulnerabilidade social como características do sujeito ou do contexto}

A EMSC surgiu com vocação de atender adolescentes usuários de drogas e que viviam grande parte do tempo nas ruas, às vezes cometendo pequenos delitos (PCR). Com o tempo, essa vocação se alterou e seu principal objetivo passou a ser "diminuir o risco de vulnerabilidade social, assim como o impacto da pobreza na vida das crianças e adolescentes da região oferecendo-lhes alternativas para a inserção social” (PCR, p. 22).

Os discursos que associam a função do projeto à redução das situações de risco e vulnerabilidade social envolvendo os adolescentes da comunidade estão presentes ainda em outros documentos e depoimentos:

Envolver crianças e adolescentes propiciando o afastamento das ruas, das drogas, violência e pequenos delitos, diminuindo sua vulnerabilidade social (PCR, p. 35).

Eficaz no trabalho com adolescentes em situação de vulnerabilidade social. (Cagaita, interação informal)

Transparece nesses textos outra forma de naturalização, bastante frequente no trabalho social educativo: a que identifica pobreza com violência ou comunidades pobres com risco e vulnerabilidade às drogas e à infração (CONCEIÇÃO; LOPES DE OLIVEIRA, 2008).

Por meio da observação etnográfica, pode-se identificar que os métodos utilizados na aproximação dos atores institucionais à realidade 
cotidiana vivenciada pelos adolescentes da EMSC eram falhos e não permitiriam bem dimensionar em que medida o contexto de origem é fonte de riscos: muitas fichas de inscrição dos adolescentes eram preenchidas de modo incompleto, e aquelas que se encontravam completas raramente eram objeto de análise dos profissionais da instituição; o relatório das visitas domiciliares realizadas por estagiários de Serviço Social não era discutido com os educadores; a participação dos familiares em encontros e reuniões não se mostrava significativa. A fragilidade das trocas com as famílias foi objeto de comentários dos próprios educadores:

Eu sinto, às vezes, falta dos pais ficarem mais inteirados, virem mais... (Gabiroba, entrevista).

Tem pai que deixa o menino aqui e não vem nem aqui ver como é que ele está. (Jatobá, entrevista)

Porque com o trabalho com a família... a gente não sabe o que está acontecendo e não tem como fazer um trabalho mais integrado das crianças com a família... e fazer nossos planejamentos. (Mangaba, entrevista)

O conhecimento limitado sobre a realidade social dos participantes contribui para generalizações indevidas, leva a que todos sejam indistintamente representados como vivenciando situações de risco e vulnerabilidade social, por serem pobres, por estarem "nas ruas" e em contato com drogas. Como efeito, conserva-se forte a crença na dimensão redentora do projeto, que, ao afastar o adolescente da rua algumas horas por semana, mantendo-o protegido no espaço institucional e apresentando-lhe outros valores e crenças que competem com os da "rua", consequentemente tornaria a clientela menos vulnerável aos circunscritores sociais de risco.

Essa parece-nos uma forma ideológica e simplista de encarar problemas que, na verdade, são muito mais complexos e multifacetados. Esses discursos e as práticas que deles advêm carregam uma visão determinista do papel do contexto social sobre os sujeitos, que contrasta com a visão dialética que permeia os documentos institucionais, nos quais identificamos, por exemplo, visões dinâmicas e abertas de desenvolvimento humano. Devemos considerar que vulnerabilidade é uma condição associada à relação do sujeito com o meio social no qual está inserido. Não é definida exclusivamente nem em termos objetivos, nem subjetivos, mas tem sua gênese na relação ativa do sujeito com as condições objeti- 
vas do meio social no qual está inserido. Uma concepção dialética de vulnerabilidade social exige compreendê-la considerando a natureza complexa, não-determinista, da relação organismo-ambiente, em que a autonomia de ambos é preservada.

Segundo Vasconcellos e Valsiner (1995), autonomia é uma condição que deve ser compreendida em relação dialética com a noção de vinculação ou identificação. A conquista da autonomia não é contraditória com senso de pertencimento ao contexto. Portanto, conceber o desenvolvimento da autonomia em sujeitos que se desenvolvem em um intricado processo dialógico com seu meio sócio-histórico exige considerar sua capacidade de, ao mesmo tempo, integrar-se ao contexto e transformá-lo, mesmo quando tal contexto se mostra canalizador de trajetórias de desenvolvimento relativamente previsíveis.

\section{Considerações finais}

Os eixos de significação analisados apresentam alguns temas recorrentes que merecem destaque nesta discussão final. O primeiro tema que iluminamos é a naturalização da adolescência, uma visão rasa e pouco reflexiva e informada do adolescer que se conecta com o desinteresse pelos estudos científicos sobre o tema. Tal ocorre não somente nos documentos institucionais, mas também nos enunciados dos diferentes atores.

Contraditoriamente, o posicionamento anterior convive com uma visão do adolescente como parceiro social, sujeito capaz de participar ativamente do contexto no qual se insere (MAGRO, 2002). É bem verdade que, entre os eixos de significação institucionais que emergiram, a discussão sobre adolescência não desce à raiz dos processos de mudança que configuram esse momento do desenvolvimento. Por outro lado, ao pautar seu trabalho no Estatuto da Criança e do Adolescente, atuando para cultivar cidadania e possibilitando um ambiente em que o adolescente é tido como sujeito ativo, o projeto acaba por preservar espaço para sua expressão, o que parece contribuir para a qualidade do vínculo dos adolescentes com o projeto.

De modo semelhante, sobressai no discurso dos profissionais da EMSC, participantes do estudo, a visão de desenvolvimento adolescente como um processo social (VYGOTSKY, 1978; 1998). Todavia, parece 
ocorrer uma confusão semântica entre construção social e influência social, em razão da qual o meio é tido como desempenhando papel determinante, inescapável. Aspectos da perspectiva sócio-histórica que transparecem em certas dimensões da concepção do projeto tornam-se aqui como que diluídos e desconsiderados.

Outro tema importante que os resultados desvelam é a visão do projeto social EMSC como espaço de proteção e cidadania, contrapondo um "lá fora" como lugar perigoso, cheio de riscos. Essa é uma discussão significativa para os projetos sociais educativos, a maior parte dos quais trabalhando com sujeitos oriundos de classes empobrecidas, que lutam contra a condição de miséria social. Nesses contextos, é preciso sempre atentar para o fato de que estar ou não em condição vulnerável é um processo bidirecional, que tanto depende das condições materiais que a realidade oferece ao sujeito quanto de os sujeitos utilizarem as ferramentas simbólicas e práticas a que passam a ter acesso para contribuir na (re)significação e transformação da realidade na qual estão inseridos. Em virtude do tempo geralmente reduzido que o adolescente passa no projeto social, comparado ao tempo que está fora dele, é fantasioso supor que este fará, sozinho, o papel de proteger o adolescente. Mais coerente é supor que o projeto atua como mediador de formas progressivamente mais críticas e conscientes que o jovem adotará frente a seu contexto comunitário, chegando a assumir papel proativo na transformação da comunidade.

A tendência dos profissionais é enfatizar a periculosidade do espaço social fora do projeto, tomando esse espaço como fonte de vulnerabilidade para crianças e adolescentes participantes. Identificamos aí uma visão infantilizante, especialmente dos adolescentes, encarados como coitadinhos, vítimas de um contexto social "perigoso" e incapazes de assumir posicionamentos autônomos frente aos riscos/eventos sociais, presentes na sua comunidade.

Também chama a atenção, na discussão das significações, o potencial identificado na arte circense para a transformação da identidade dos participantes do projeto. Os profissionais revelam crer nesse potencial da arte circense ao convertê-la em principal objeto do acompanhamento e avaliação dos adolescentes, que considera, sobretudo, sua desenvoltura na realização das técnicas e no uso dos instrumentos que configuram a arte circense. Se a formação do artista circense não constitui a meta do projeto, eis aí uma contradição. 
Entendemos que algumas das significações institucionais aqui relatadas, ao tratarmos do caso particular de um projeto socioeducativo, refletem visões presentes em outros projetos do sistema de ações socioeducativas. Yokoy Souza (2007) identificou elementos muito similares, no que se refere à precariedade das reflexões sobre as crenças e valores, carregadas de estigma e preconceito, que orientam as práticas e intervenções em uma instituição de abrigamento de adolescentes e jovens infratores, em regime de semiliberdade.

Enfim, procuramos, com este estudo, contribuir para iluminar questões relevantes que fomentem o conhecimento sobre o papel que projetos sociais educativos podem desempenhar na promoção do desenvolvimento humano. Considerando tais projetos sociais como microcontextos de desenvolvimento, temos que a qualidade das trocas sociais ali potencializadas e o sistema de valores em que essas trocas são significadas são elementos essenciais para que trajetórias de desenvolvimento inovadoras possam ser concebidas. Nesse sentido, é necessário o comprometimento com uma visão de desenvolvimento pessoal como processo dialético e complexo, marcado por um imbricamento de aspectos internos e externos (VALSINER, 1994a; VALSINER, 1989; VYGOTSKY, 2003), em que é reconhecido o papel ativo desse sujeito na construção de si e são potencializadas as trocas em que tal papel ativo se expressa. 


\section{Referências}

AGUIAR, Wanda Maria J.; OZELLA, Sérgio. O sentido subjetivo atribuído à escolha profissional: um estudo com jovens de camadas populares. In: OZELLA, Sérgio. (Org.), Adolescências construidas: a visão da psicologia sócio-histórica. São Paulo: Cortez, 2003. p. 253-276.

ANDRIANI, Ana Gabriela P. O significado construído por jovens negros pertencentes a camadas populares sobre a escolha do futuro profissional. In: OZELLA, Sérgio. (Org.), Adolescências construidas: a visão da psicologia sócio-histórica. São Paulo: Cortez, 2003. p. 223-252.

ARENDT, Ronald João J. Investigações em torno do objeto da psicologia. In: MANCEBO Deise; JACÓ-VILELA Ana Maria (Orgs.). Abordagens sócio-históricas e desafios contemporâneos. Rio de Janeiro: EdUERJ. 2004. p. 19-34.

BAUER, Martin W.; AARTS, Bas. A construção do corpus: um princípio para a coleta de dados qualitativos. In: BAUER, Martin W.; GASKELL, George (Orgs). Pesquisa qualitativa com texto, imagem e som. Petrópolis: Vozes, 2002. p. 39-63.

BOCK, Ana Mercês B. A perspectiva sócio-histórica de Leontiev e a crítica à naturalização da formação do ser humano: A adolescência em questão. Cadernos CEDES, Campinas, v. 24, n. 62, p. 26-43, abr. 2004.

BOCK, Ana Mercês B. A adolescência como construção social: estudo sobre livros destinados a pais e educadores. Psicologia, escola e educacional, Campinas, v. 11, n. 1, p. 63-76, jan./jun. 2007.

BOCK, Ana Mercês B.; LIEBESNY, B. Quem eu quero ser quando crescer: um estudo sobre o projeto de vida de jovens em São Paulo. In: OZELLA, Sérgio (Org.), Adolescências construídas: a visão da psicologia sócio-histórica. São Paulo: Cortez, 2003. p. 203-222.

BRANCO, Angela Uchoa; VALSINER, Jaan. Changing methodologies: A co-constructivist study of goal orientaions in social interactions. Psychology and Developing Societies, v. 9, n. 1, p. 35-64, 1997.

BRANCO, Ângela Uchoa; ROCHA, Rivane Ferraz. A questão da metodologia na investigação científica do desenvolvimento humano. Psicologia: Teoria e Pesquisa, Brasília, v. 14, n. 3, p. 251-258, 1998.

BRUNER, Jerome. Realidade mental, mundos possiveis. Porto Alegre: Artmed 2002. 211p. CONCEIÇÃO, Maria Inês Gandolfo; LOPES DE OLIVEIRA, Maria Cláudia S. A relação adolescente-drogas e as perspectivas da nova legislação sobre drogas. Revista de Informação Legislativa, Brasília, v. 45, n. 180, p. 253-262, out./dez. 2008.

DESSEN, Maria Auxiliadora; POLONIA, Ana da Costa. A família e a escola como contextos de desenvolvimento humano. Paidéia, Ribeirão Preto, v. 17, n. 36, p. 21-31, jan./abr. 2007.

ESPÍNDULA, Daniel Henrique P.; SANTOS, Maria de Fátima S. Representações sobre a adolescência a partir da ótica dos educadores sociais de adolescentes em conflito com a lei. Psicologia em Estudo, Maringá, v. 9, n. 3, p. 357-367, set./dez. 2004.

GASKELL, George. Entrevistas individuais e grupais. In: BAUER, Martin W.; GASKELL, George (Orgs). Pesquisa qualitativa com texto, imagem e som. Petrópolis: Vozes, 2002. p. 64-89.

GONDRA, José; GARCIA, Inára. A arte de "endurecer miolos moles e cérebros brandos": a racionalidade médico-higienista e a construção social da infância. Revista Brasileira 
de Educação, n. 26, p. 70-84, maio/ago. 2004.

GONZÁLEZ REY, Fernando. Pesquisa qualitativa e subjetividade: Os processos de construção da informação. São Paulo: Thomson, 2005. 205p.

KAPLAN, B.; DUCHON, D. Combining qualitative and quantitative methods in information systems research: a case study. Mis Quarterly, v. 12, n. 4, p. 571-586, 1988.

LOBO, Lilia Ferreira; CASSOLI, Tiago. Circo social e práticas educacionais não-governamentais. Psicologia e Sociedade, Porto Alegre, v. 18, n. 3, p. 62-67, set. 2006.

LOPES DE OLIVEIRA, Maria Cláudia Santos. Subjetividade e conhecimento: do sujeito da representação ao sujeito dialógico. Revista Fractal do Departamento de Psicologia da UFF, Niterói-RJ, v. 15, n. 2, p. 33-52, jan./jun. 2003.

LOPES DE OLIVEIRA, Maria Cláudia Santos. Identidade narrativa e desenvolvimento na adolescência: uma revisão crítica. Psicologia em estudo, Maringá, v. 11, n. 2, p. 427-436, maio/ago. 2006.

MACLAREN, Peter. Multiculturalismo revolucionário. Porto Alegre: Artmed, 2000.

MADUREIRA, Ana Flávia do Amaral; BRANCO, Ângela Uchoa. A noção de sujeito na ciência psicológica: linguagem e constituição da subjetividade em discussão. In: GONZÁLEZ REY, Fernando (Org). Subjetividade, complexidade e pesquisa em psicologia. São Paulo: Thomson, 2005a. p. 127-153.

MADUREIRA, Ana Flávia do Amaral; BRANCO, Ângela Uchoa. Construindo com o outro: uma perspectiva sociocultural construtivista do desenvolvimento humano. In: DESSEN, Maria Auxiliadora; COSTA JUNIOR, Ánderson Luiz (Orgs). A Ciência do Desenvolvimento Humano. Porto Alegre: Artmed, 2005b. p. 90-109.

MAGRO, Viviane Melo M. Adolescentes como autores de si próprios: cotidiano, educação e o Hip Hop. Cadernos Cedes, Campinas, v. 22, n. 57, p. 63-75, ago. 2002.

MUNHOZ, Silmara C. D.; MACIEL, Diva Albuquerque. Interação família-criança: possibilidades de negociação na co-construção da escrita. Revista Fractal do Departamento de Psicologia da UFF, Niterói-RJ, v. 20, n. 1, p. 269-284, 2008.

OLIVEIRA, Marta Kohl. Vygotsky e o processo de formação de conceitos. In: DE LA TAILlE, Yves; OLIVEIRA, Marta Kohl; DANTAS, Heloysa Piaget, Vygotsky, Wallon: teorias psicogenéticas em discussão. São Paulo: Summus, 1992. p. 23-24.

ORIONTE, Ivana; SOUZA, Sônia Margarida G. Viver em abrigo: com a palavra a criança. Pesquisas e práticas psicossociais, São João Del-Rei, v. 2, n. 1, p. 101-116, mar./ago. 2007. OZELLA Sérgio. A adolescência e os psicólogos: a concepção e a prática dos profissionais. In: OZELLA, Sérgio (Org). Adolescências construidas: a visão da psicologia sócio-bistórica O. São Paulo: Cortez, 2003. p. 17-40

OZELLA Sérgio; AGUIAR, Wanda Maria J. Desmistificando a concepção de adolescência. Cadernos de Pesquisa, São Paulo, v. 38, n. 133, p. 97-125, jan./abr. 2008.

PALMIERI, Marilícia Witzler A.; BRANCO, Ângela Uchoa. Cooperação, competição e individualismo em uma perspectiva Sócio-cultural Construtivista. Psicologia: Reflexão e Crítica, Porto Alegre, v. 17, n. 2, p. 189-198, 2004

RAPOSO, Mírian Barbosa T.; MACIEL, Diva Albuquerque. A Psicologia e a formação docente: uma contribuição do sociocultural construtivismo. Linhas Críticas, Brasília, v. 12, n. 22, p. 91-108, jan./jun. 2006.

RAPOSO, Mírian Barbosa T.; MACIEL, Diva Albuquerque. A formação de professores para o início da escolarização: uma reflexão a partir da abordagem sociocultural constru- 
tivista. Revista Brasileira de Estudos Pedagógicos, Brasília, v. 88, n.220, p. 592-620, 2007.

ROSA, Elisa Zaneratto. Da rua para a cidadania: a construção de sentidos na construção da travessia. In: OZELLA, Sérgio (Org). Adolescências construidas: a visão da psicologia sóciohistórica 0. São Paulo: Cortez, 2003. p. 167-200.

SANTANA, Juliana Prates, DONINELLI, Thaís Mesquista, FROSI, Raquel Valiente; KOLLER, Silvia Helena. Instituições de atendimento a crianças e adolescentes em situação de rua. Psicologia \& Sociedade, Florianópolis-SC, v. 16, n. 2, p. 59-70, maio/ago. 2004. SANTANA, Juliana Prates, DONINELLI, Thaís Mesquista, FROSI, Raquel Valiente; KOLLER, Silvia Helena. Os adolescentes em situação de rua e as instituições de atendimento: utilizações e reconhecimento de objetivos. Psicologia: Reflexão e Crítica, Porto Alegre, v.18, n. 1, p. 134-142, jan./abr. 2005

SANTOS, Érica Piedade dos. (Des)construindo a 'menoridade': uma análise crítica sobre o papel da Psicologia na produção da categoria "menor”. In: GONÇALVES, Hebe Signorini; BRANDÃO, Eduardo Pontes (Orgs). Psicologia jurídica no Brasil. Nau. Rio de Janeiro, 2004. p. 205-248.

SILVA, Ana Paula Soares da; ROSSETTI-FERREIRA, Maria Clotilde; CARVALHO, Ana Maria Almeida (2004) Circunscritores: limites e possibilidades no desenvolvimento. In: _. (Orgs). Rede de significacoões e o estudo do desenvolvimento humano (pp. 81-91). São Paulo: Artmed.

SMOLKA, Ana Luiza Bustamante. Sobre significação e sentido: uma contribuição à proposta de rede de significações. In: ROSSETTI-FERREIRA, Maria Clotilde; AMORIM, Kátia de Souza; SILVA, Ana Paula Soares da; CARVALHO, Ana Maria Almeida (Orgs). Rede de Significações e o estudo do desenvolvimento humano. Porto Alegre: Artmed, 2004. p. 3549.

SZELBRACIKOWSKI, Adriane Corrêa; DESSEN, Maria Auxiliadora. Problemas de comportamento exteriorizado e as relações familiares: revisão de literatura. Psicologia em Estudo, Maringá, v. 12, n. 1, p. 30-40, jan./abr. 2007.

TEIXEIRA, Lumena Celi. Sentido subjetivo da exploração sexual para uma adolescente prostituída. In: OZELLA, Sérgio (Org.), Adolescências construídas: a visão da psicologia sóciohistórica. São Paulo: Cortez, 2003. p. 105-136.

TACCA, Maria Carmen Villela R.; BRANCO, Ângela Uchoa. Processos de significação na relação professor-aluno: uma perspectiva sociocultural construtivista. Estudos de Psicologia, Natal, v. 13, n. 1, p. 39-48, 2008.

TACCA, Maria Carmen Villela R.; GONZÁLEZ REY, Fernando. Produção de sentido subjetivo: as singularidades dos alunos no processo de aprender. Psicologia Ciência e Profissão, Brasília, v. 28, n. 1, p.138-161, mar. 2008.

VALSINER, Jaan. Culture and the development of children's action. Chichester: Wiley, 1987.

VALSINER, Jaan. Human development and culture: the social nature of personality and its study. Lexington: Lexington Books, 1989. p. 1-42.

VALSINER, Jaan. Culture and development: a co-constructivist perspective. In: VAN GEERT, P.; MOS, L. P.; BKER, W. J. (Eds.). Annals of theorical, 10. New York: Plenum, 1994a.

VALSINER, Jaan. Bidirectional cultural transmission and constructive sociogenesis. In: GRAAF, W. de; MAIER, R. (Orgs.), Sociogenesis reexamined. New York: Springer, 1994b. p. 47-70. 
VASCONCELLOS, Vera M. R; VALSINER, Jaan. Perspectiva co-construtivista na Psicologia e na Educação. Porto Alegre: Artmed, 1995. 102p.

VECTORE, Célia. Estratégias mediacionais: possibilidades de inserção do psicólogo escolar/educacional em abrigos. In: MARTINEZ, Albertina Mitjáns (Org.), Psicologia Escolar e compromisso social. Campinas: Alínea, 2005. p. 155-175.

VYGOTSKY, Lev Semenovich. Mind in society: The development of higher psychological processes. Cambridge: Harvard University Press, 1978.

VYGOTSKY, Lev Semenovich. Pensamento e linguagem. São Paulo: Martins Fontes, 1998. $194 p$.

VYGOTSKY, Lev Semenovich. A formação social da mente. São Paulo: Martins Fontes, 2003. 191p.

YOKOY SOUZA, Tatiana. Um estudo dialógico sobre institucionalização e subjetivação de adolescentes em uma casa de semiliberdade. 2007. p. 191. Dissertação (Mestrado em Psicologia). Universidade de Brasília, Brasília, 2007.

\section{Notas}

1 Projeto Pedagógico contendo atividades pedagógicas; rotina pedagógica da EMSC; processo avaliativo e cronograma do ano de 2007.

2 Projeto para captação de recursos financeiros contendo a apresentação do projeto social EMSC.

3 Todos os nomes dos participantes que aparecem neste texto são fictícios.

Recebido: 04/09/2009

Aprovado: 21/05/2010

Contato:

Universidade de Brasília

Campus Universitário Darcy Ribeiro

Brasília - DF

CEP 70910-900 